\title{
El proceso electoral 2006 y sus innovaciones en el sistema democrático peruano
}

A Valentín Paniagua, catedrático y amigo

José Francisco Gálvez

\section{Introducción}

Desde que en el Perú se establecieran los procesos electorales en el siglo XIX, con el objeto de renovar los cargos políticos, se han producido una serie de innovaciones en materia electoral con la finalidad de ir afianzando nuestro sistema democrático. El proceso electoral de 2006 no ha sido la excepción.

A semejanza del modelo occidental, la democracia peruana del siglo XIX partió de los criterios planteados por el liberalismo y la Ilustración, es decir, la revaloración de los llamados principios, leyes o derechos naturales siguiendo una concepción racionalista que proponía el reconocimiento y defensa, por parte de la sociedad política, de la libertad, la propiedad y la seguridad.

El bien jurídico por excelencia era la ansiada libertad, regulada desde el Derecho por Roma bajo la categoría del status libertatis, que reconocía tácitamente la protección a la vida. Otro referente era la propiedad, que desde la Antigüedad era también uno de los requisitos para participar en las elecciones, sea como elector o como representante. Se trataba más de la propiedad inmueble, es decir de la tierra como origen de la riqueza, tesis planteada en la teoría de La riqueza de las naciones (1776) de Adam Smith. Más adelante, la creatividad francesa, en palabras de Benjamín Constant en su teoría política (1815), incorporaría los matices de la propiedad mueble, representada por el comercio, la propiedad intelectual o de las ideas, presentes en todo su fulgor durante la Segunda Revolución Industrial. Y finalmente, la seguridad ante cualquier arbitrariedad o exceso de poder, en un principio, de parte del monarca o su representante, y más adelante, también de los particulares. Estos derechos irán acompañados de aquellos elaborados por la propia sociedad como producto

Abogado. Profesor de Derecho Constitucional e Historia del Derecho Peruano. Doctor en Historia por la Universidad Complutense de Madrid. Investigador del Instituto Riva-Agüero. 
de la convivencia humana dada su naturaleza gregaria: el derecho de asociación, la libertad de expresión, la inviolabilidad del domicilio, el secreto de correspondencia, etcétera.

En lo que se refiere a los procesos electorales, los derechos naturales - luego denominados individuales - serán retomados como requisitos para convertirse en ciudadano, y por ende en sufragante, generándose el llamado voto censitario: ser mayor de edad y letrado, tener arte, oficio o profesión, gozar de renta y ser avecinado o residente. Era impensable tener electores y más aún representantes que carecieran de recursos, pues se temía que, de ser elegidos, esas nuevas autoridades fueran en contra de la sociedad de propietarios. De ahí que el sistema representativo optase por someter a un proceso de calificación a los nacionales para convertirlos en ciudadanos, lo que en Francia se entendió como que solo había una posibilidad de aumentar la población electoral: enriquecerse.

En los pilares de nuestro sistema electoral, a los criterios ya mencionados para ser considerado ciudadano, se agregó el de ser católico, debido a que la religión católica, apostólica y romana fue proclamada la oficial. ${ }^{1}$ Por eso, hasta 1896 las mesas electorales se organizaban desde las parroquias. De acuerdo a la conformación corporativa de la sociedad, se exceptuaba de la participación política a quienes, aun siendo libres, se desempeñaban como jornaleros, domésticos o quienes se encontrasen en una situación de subordinación. El sistema de elecciones preveía, en cambio, la presencia de militares, en calidad de oficiales, y de clérigos, en su mayoría seculares, a quienes no se les exigía con la misma severidad la renta establecida en las constituciones.

Los procesos electorales fueron afinándose con las leyes y las circunstancias, alternándose los regímenes representativos con los gobiernos de facto, que urgían ser legitimados con un nuevo Congreso. En su momento, este proceso permitió incrementar temporalmente la población de sufragantes con personas que aun siendo iletradas, poseían talleres o industrias, es decir eran tributarias. Este último elemento también fue considerado por la doctrina occidental bajo el razonamiento de que quien contribuye con el Estado, vota.

Podemos apreciar que el sufragio no nació como el derecho que hoy poseemos sino que se encontraba adscrito a una función social, conservando la calidad de privilegio por su relación con el ejercicio del poder a través del ejercicio de la soberanía, expresado en el voto. Los siglos XIX y XX nos demuestran el interés de diversos grupos sociales por vincularse al Estado e identificarse con el sistema representativo de entonces. A ello contribuirán nuevas interpretaciones del papel que debe cumplir el sujeto, propiciándose innovaciones en el marco jurídico vigente. Si antes la Constitución era el referente político y declarativo

Ser católico era también indispensable para acceder a un empleo público. 
y los códigos representaban la nueva legalidad, veremos que ambos textos se articularán sistemáticamente, colocando a la Constitución como el nuevo eje político y jurídico, con lo cual el ejercicio de los derechos será capital, en tanto facultades, antes naturales luego individuales y posteriormente recreadas bajo la óptica de los derechos humanos.

Este fundamento debe ser ponderado paralelamente con la reforma del Estado que se propicie y que permita un ejercicio armonioso, evitando actitudes radicales que solo pretenden menoscabar la institucionalidad existente. El último proceso electoral nos deja como aportes la reforma constitucional que permitió ejercer el derecho al sufragio a policías y militares, el establecimiento de la barrera electoral (ley 28617) que modifica la Ley Orgánica de Elecciones (ley 26859), así como la Ley de Partidos Políticos (ley 28094), no descartándose plantear la no reelección para los cargos congresales. Quedan como tareas pendientes el derecho al voto para los presos no sentenciados y la eliminación del voto preferencial.

\section{Retomando el derecho al sufragio de policías y militares}

El liberalismo conservó a la corporación militar en el nuevo diseño, manteniéndose el interés de la autoridad por otorgar seguridad a este grupo, dotándolo de una serie de privilegios, como poder usar armas en todo momento, salvo cuando estuviese en las dependencias del monarca, y no poder ser embargado, salvo por la Real Hacienda, preferencia última que sería extensible a las viudas, hijos y criados. ${ }^{2}$ Más adelante, durante el período de las cortes generales y extraordinarias reunidas en Cádiz, se propusieron cambios acorde con la teoría francesa del poder, estableciéndose atribuciones para el Ejecutivo, Legislativo y Judicial. Los diarios de debates correspondientes señalan que en la redacción de la Constitución, el diputado por el Principado de Asturias, Agustín de Argüelles, sostuvo que la Comisión de Constitución había pensado mantener a los militares en su fuero por considerarlos indispensables para la disciplina y organización, derivando a la ordenanza respectiva su regulación donde se debía conciliar:

[...] el objeto de la institución militar y el respeto debido a las leyes y a las autoridades. El soldado es un ciudadano armado solamente para la defensa de su patria; un ciudadano que, suspendiendo la tranquila e inocente ocupación de la vida civil, va a proteger y conservar con las armas, cuando es llamado por la ley, el orden público en lo interior y hacer respetar la nación [...].3

Cruz Barney, Óscar. Historia del Derecho en México. México: Oxford Press, 2002, p. 340.

Argüelles, Agustín de. Discurso preliminar a la Constitución de 1812. Madrid: Centro de Estudios Constitucionales, p. 100. 
Esta postura se afirmaría en el texto final de la Constitución Política de la Monarquía Española de 1812, promulgada para todos los dominios del imperio español, cuyo artículo 250 establecía que: «Los militares gozarán también de fuero particular, en los términos que previene la ordenanza o en adelante previniere». ${ }^{4}$ Así, la jurisdicción de guerra conservó no solo el juzgamiento de los delitos o faltas militares sino que como fuero personal, incluía todo litigio, desde el incumplimiento de contrato hasta otros actos civiles de mero trámite. ${ }^{5}$ Esto no era de extrañar porque dichas características recogían el carácter estamental de la sociedad así como las facultades para cada cuerpo social.

En la Constitución peruana de 1828 se recalcaba las limitaciones de la fuerza de seguridad, en tanto parte del Estado, estableciéndole restricciones. Así, el artículo 146 estipulaba que: «La fuerza pública es esencialmente obediente: no puede deliberar», ${ }^{6}$ lo que no afectaba a los miembros en sí pues cabía la posibilidad de votar y de ser elegido, compatibilidad natural en el incipiente derecho constitucional del siglo XIX. Más adelante, la Carta de 1860 estipuló en su artículo 119: «El objeto de la fuerza pública es asegurar los derechos de la Nación en el exterior y la ejecución de las leyes y el orden en el interior. La obediencia militar será arreglada a las leyes y ordenanzas militares».?

Ello dejaba entrever que el poder de facto con que contaban estas personas quedaba condicionado al orden jurídico estatal, y por otro lado, se creaba un perfil del militar separado de la sociedad civil, entendiéndose como un orden aparte, desvinculado del resto de la legislación, de los preceptos consti-tucionales y de las normas del fuero común. En opinión de Rómulo Lanatta, el tenor de dicho articulado generaba una apreciación inexacta pues: «[...] el expresado artículo de la Constitución de 1860, que la vigente Carta política (1933) ha reproducido, no tiene ya indudablemente aquel sentido»..$^{8}$ Sin embargo, más allá de la pertenencia a la institución, el militar como cualquier individuo: "[...] puede mantener sus propias creencias en materia religiosa, sus propias aficiones y su propia postura política, por lo tanto cada militar, a título personal, podría participar en actividades políticas fuera de los cuarteles». ${ }^{9}$ Fue el general César Canevaro, representante por Huancavelica, el último militar en

\footnotetext{
España. Constitución Política de la Monarquía Española. Artículo 250.

«Sucesión testamentería del general Domingo Orué». En El Comercio, 1839.

6 Ugarte del Pino, Juan Vicente. Historia de las constituciones del Perú. Lima: Editorial Andina. 1978; p. 248.

7 García Belaunde, Domingo. Las constituciones del Perú. Tomo II. Lima: Fondo Editorial de la Universidad San Martín de Porres, 2006, p. 33.

8 Lanatta, Rómulo E. Curso de justicia militar. Lima: 1935, p. 16.

9 Guerra Martinière, Margarita. «Del voto militar». En Elecciones (Lima), Revista de la Oficina Nacional de Procesos Electorales (ONPE), año 2, nº 2, diciembre 2003, pp. 117-139.
} 
actividad elegido para un cargo político en el Perú, desempeñándose como presidente del Senado en 1922.

La Asamblea Constituyente de 1931 recogió en los diarios de debates la inquietud de un sector de políticos por controlar el fenómeno del militarismo, cuyo ascenso cubría el vacío de poder de los regímenes representativos y terminaba por propiciar el menoscabo institucional. Para ello restringió la participación política a los miembros de la fuerza pública mediante el voto. Sin embargo, cuando analizamos la situación de aquellos que irrumpieron valiéndose de golpes de estado (como Luis Miguel Sánchez Cerro o Manuel A. Odría), quienes más tarde hicieron que su autoridad fuese legítima o aquel general convocado por el Congreso para concluir un mandato presidencial (Óscar R. Benavides), nos percatamos que ninguno de ellos renunció a su condición de estar en actividad pese a ocupar el cargo de Presidente de la República. Más adelante, el sistema electoral se vio cuestionado por la influencia gradual de la Declaración Universal de Derechos Humanos, ${ }^{10}$ iniciándose un proceso de ampliación en el desarrollo de dichos derechos para militares, por vía normativa e interpretativa, sobre todo a partir de 1978, cuando el Perú pasaba a articularse con una jurisdicción supranacional, a través del Pacto de San José: ${ }^{11}$

\section{Artículo 21}

1. Toda persona tiene derecho a participar en el gobierno de su país, directamente o por medio de representantes libremente escogidos.

2. Toda persona tiene el derecho de acceso, en condiciones de igualdad, a las funciones públicas de su país.

3. La voluntad del pueblo es la base de la autoridad del poder público; esta voluntad se expresará mediante elecciones auténticas que habrán de celebrarse periódicamente, por sufragio universal e igual y por voto secreto u otro procedimiento equivalente que garantice la libertad del voto.

$[\ldots]$

\section{Artículo 23. Derechos Políticos}

1. Todos los ciudadanos deben gozar de los siguientes derechos y oportunidades:

a) de participar en la dirección de los asuntos públicos, directamente o por medio de representantes libremente elegidos;

b) de votar y ser elegidos en elecciones periódicas auténticas, realizadas por sufragio universal e igual y por voto secreto que garantice la libre expresión de la voluntad de los electores, y

10 Declaración Universal de Derechos Humanos. Adoptada y proclamada por la Asamblea General en su resolución 217 A (III), del 10 de diciembre de 1948. Incorporada en el sistema normativo peruano por resolución legislativa 13282 del 9 de diciembre de 1959.

11 Convención Americana sobre Derechos Humanos (Pacto de San José), suscrita en la Conferencia Especializada Interamericana sobre Derechos Humanos, San José, Costa Rica, 7 al 22 de noviembre de 1969. Aprobada y ratificada por el Estado peruano mediante por el decreto ley 22231 del 28 de julio de 1978. 
c) de tener acceso, en condiciones generales de igualdad, a las funciones públicas de su país.

Durante la década de 1990 y en los momentos álgidos del terrorismo, el gobierno de Alberto Fujimori Fujimori concedió a los militares destacados en las zonas de emergencia que eran gobernadas por los comandos político-militares, el uso del documento nacional de identidad (DNI). Ello se hizo atendiendo a las circunstancias por las que atravesaban los miembros de seguridad, con el fin de evitar que fueran reconocidos por los miembros de Sendero Luminoso (SL) y del Movimiento Revolucionario Túpac Amaru (MRTA) mientras durase su servicio.

Con el retorno del régimen representativo, se quiso regularizar esta situación y evitar la ambivalencia que tenían los uniformados, incluso en la celebración de sus actos jurídicos, que como apreciamos mantenía parte de ese rezago del fuero privativo. Por resolución jefatural 789-2005/RENIEC se estipuló el uso obligatorio del DNI entre los policías y militares en actividad a partir del 1 de agosto de 2005 para acreditar la identidad de las personas naturales, al margen de la ocupación, oficio o profesión que desempeñasen y en los casos que señalaba la ley: actos civiles, comerciales, administrativos, notariales, judiciales y policiales, así como para intervenir en procesos judiciales y administrativos; realizar cualquier acto notarial; celebrar cualquier tipo de contrato; obtener pasaporte; e inscribirse en cualquier sistema de seguridad social, entre otros. Conforme a los artículos 26 y 27 de la ley 26497 o Ley Orgánica del Registro Nacional de Identificación y Estado Civil (RENIEC), el DNI representa el documento público, personal e intransferible, de uso obligatorio para todos los ciudadanos nacionales.

De este modo, se cerraba un proceso en el que los policías y militares se hallaban excluidos del sistema de identificación que abarcaba a la mayoría de la población, y que en su momento había sido cuestionado porque se aducía una estrategia encubierta mediante la que los miembros de las fuerzas de seguridad favorecían a la autocracia del régimen de Alberto Fujimori Fujimori, dado que el sistema electoral se realizaba por distrito único, no requiriendo más de cuatro mil votos para lograr un escaño congresal. En la propuesta para un acuerdo político nacional suscrita por los doctores Javier de Belaunde López de Romaña, Francisco Eguiguren y Rudecindo Vega Carreazo, y dejada a consideración de la Asamblea General de la Organización de Estados Americanos (OEA) del año 2000 en Windsor, Canadá, ${ }^{12}$ se estipulaba lo siguiente:

2 «Propuesta para un acuerdo político nacional». Lima, 26 de junio del 2000. En http:// www.transparencia.org.pe/web/pronunciamientos/acuerdo.rtf. 


\section{Padrón electoral}

Elaborar un nuevo padrón electoral, teniendo en cuenta los siguientes criterios:

a. Reinscripción gratuita y obligatoria de ciudadanos con Libretas Electorales manuales y mecanizadas.

b. Canje de DNI o duplicados gratuitos.

c. Depuración automática de ciudadanos que no votaron en los tres últimos procesos electorales (las municipales de 1995, 1998 y 2000).

d. Depuración de miembros de Fuerzas Armadas, bajo sanción destitución del Jefe del Comando Conjunto de las Fuerzas Armadas y del Jefe de la Policía Nacional.

El inciso d se refería enfáticamente a la colusión entre ciertos policías y militares y la corrupción del gobierno de turno, la misma que no fue exclusiva de los uniformados pues comprometió a diferentes sectores de la sociedad. Con el inicio de la legislatura del período 2001-2002, el 27 de julio de 2001, los congresistas Mercedes Cabanillas Bustamante y José Luis Delgado, del Partido Aprista Peruano, propusieron la reforma constitucional mediante un proyecto de ley con la intención de que sufragaran los miembros de las Fuerzas Armadas y de la Policía Nacional, proyecto derivado más adelante a la Comisión de Constitución, que buscaba extender el derecho al voto a quienes desde la Constitución de 1933 se les había prohibido: «Art. 87: No pueden votar los que tengan en suspenso el ejercicio de la ciudadanía y los miembros de la Fuerza Armada mientras se hallen en servicio. No hay otras inhabilitaciones».

Estos documentos establecerían el ejercicio del derecho al sufragio como incondicional de todo individuo. Pese a que el Perú los ratificó en su momento, con lo cual se incluía ese ejercicio en su sistema normativo, no se había establecido aún su compatibilidad con la Carta constitucional. Bajo el criterio de la universalidad y separándolo de toda restricción por raza, sexo, idioma, confesión o convicción política, varios países de la región, como Argentina, Chile, México, Paraguay, Uruguay y Venezuela fueron adoptándolo.

En el Perú, después de tres largos años, el 12 de octubre de 2004, la Comisión de Constitución y Reglamento del Parlamento aprobó el proyecto que concluyó con la ley 28480 que establece que los miembros de las Fuerzas Armadas y de la Policía Nacional tienen derecho al voto y a la participación ciudadana regulada por ley. Ello demandaba la reforma constitucional de los artículos 31 y 34 de la Constitución Política vigente en dos legislaturas. Finalmente, quedó expedito su derecho a participar en los comicios presidenciales, congresales, municipales y regionales del año 2006.

Sin embargo, los miembros de las Fuerzas Armadas y de la Policía Nacional no podrán postular a cargos públicos, participar en actividades partidarias o manifestaciones ni realizar actos de proselitismo mientras se encuentren en servicio activo. Otros derechos y libertades que la actual Constitución establece, pero 
que están limitados para quienes son militares y policías en actividad son: artículo 2, inciso 3: el derecho a emitir opinión en asuntos públicos o de seguridad nacional. Con el mismo criterio queda restringido lo estipulado por el inciso 4 que establece la libertad de información, opinión y expresión, difusión de pensamiento; lo señalado en el inciso 11: la posibilidad de que el individuo elija libremente su lugar de residencia o pueda entrar o salir del país, sin sujeción de su comando. Tampoco pueden ejercer el derecho a participar en forma individual o colectiva en la vida política, a promover la facultad de remoción, la revocatoria de autoridades, proponer una iniciativa legislativa y un referendo, esto último vinculado al sufragio mismo en la medida en que es factible someter a consulta popular los lineamientos constitucionales. Tampoco está contemplado, por el momento, el derecho a formular peticiones colectivas ni lo señalado en el inciso 22 que otorga el disfrute del tiempo libre y al descanso. De otro lado, no está dentro del libre ejercicio de los uniformados en el Perú el hecho de prestar trabajos sin su libre consentimiento, mientras que los artículos 28 y 42 se refieren a la posibilidad de ejercer los derechos de sindicalización, negociación colectiva y huelga, y los artículos 31 y 34, al derecho a participar en asuntos públicos, ellos terminan siendo incompatibles en el actual escenario con los ejercicio de derechos de carácter constitucional. De ahí que la vida militar policial, en tanto no se vincule más con la civilidad de manera institucional, deberá ajustarse a una serie de restricciones en el ejercicio de los derechos antes mencionados.

Además de la corrupción, en los últimos años hubo en las campañas de proselitismo una serie de prácticas éticamente cuestionables, sea porque quien las realizaba se aprovechaba de su cercanía al poder, sea porque buscaba identificarse con determinado sector social, vulnerando la reglamentación. Nos referimos a lo ocurrido durante una visita del entonces presidente Alberto Fujimori Fujimori al interior del país, en la que el propio general y jefe de la región militar repartía almanaques a los pobladores con la foto del mandatario, o el caso de aquella candidata al Congreso por Unidad Nacional (UN) por la representación de Lima, una ex teniente de la Policía Nacional que se presentaba vistiendo el uniforme como si continuase en actividad. Estas son prácticas que deben descartarse de plano, con ayuda de los medios de comunicación, pues terminan vulnerando el proceso electoral, y que desde el año 2000 son fiscalizadas por la Defensoría del Pueblo. ${ }^{13}$

De esta manera, según las fuentes del Registro Nacional de Identificación y Estado Civil (RENIEC) y de la Oficina Nacional de Procesos Electorales (ONPE), 138.156 efectivos (19.883 del Ejército; 20.500 de la Marina; 9.995

Véase Defensoría del Pueblo. Elecciones 2000. Supervisión de la Defensoría del Pueblo. Lima: Defensoría del Pueblo, Lima, 2000. 
de la Fuerza Aérea; y 87.778 de la Policía Nacional) tuvieron expedito su derecho al sufragio en las mesas de votaciones respectivas. Debemos descartar la antojadiza opinión de que el voto pertenece a la Fuerza Armada en su conjunto ya que en realidad se trata del ciudadano, uniformado o no, quien posee dicha facultad, la que se materializará en su simpatía por determinado partido o fuerza política. De la misma manera, si además de ciudadano, en tanto fuerza de seguridad esta persona tiene la misión de custodiar el desenvolvimiento normal del proceso electoral, es dable que la ONPE le otorgue las facilidades del caso para cumplir con el sufragio, y no como cierto medio de comunicación dejaba entrever, que los uniformados pasan por encima de cualquier ciudadano para votar. La experiencia demuestra que la devolución del voto al ciudadano uniformado más que socavar al instituto castrense o policial terminará por afianzar su participación real en el sistema electoral vigente y en la sociedad civil de la que forma parte como persona.

\section{La barrera o valla electoral}

Tradicionalmente, el sistema de representación ha vinculado íntimamente el voto con la renovación de los cargos políticos — diputados, a los que se añadirán más adelante los senadores y el Presidente de la República—, pero además con la participación calificada de los ciudadanos, desarrollada a través de un nivel de organización: clubes y partidos políticos. Gradualmente, los procesos electorales fueron involucrando a los diferentes actores sociales que más adelante serían políticos: la mujer ${ }^{14}$ y el analfabeto. La presencia de ambos se hallaba en la discusión de la intelectualidad peruana, como lo manifestara José Luis Bustamante y Rivero, ${ }^{15}$ pero a pesar de los proyectos de ley y debates al interior del recinto congresal, no habían logrado el respaldo mayoritario de la clase política de entonces. La participación de la mujer como electora y representante se concretaría en las elecciones presidenciales y congresales de 1956. En cuanto a los analfabetos, la Asamblea Constituyente de 1978 recogió lo estipulado en la Convención Americana sobre Derechos Humanos suscrita en 1969, facilitando su incorporación definitiva en la Constitución de 1979:

Art. $65^{\circ}$ Son ciudadanos los peruanos mayores de dieciocho años. Para el ejercicio de la ciudadanía se requiere estar inscrito en el Registro Electoral.

14 Ley 12391, promulgada el 7 de septiembre de 1955.

15 Bustamante y Rivero, José Luis. «El problema de la democracia». En Mensaje al Perú. Lima: Editorial Universitaria, s/f. 
Tienen derecho de votar todos los ciudadanos que están en el goce de su capacidad civil. El voto es personal, igual, libre, secreto y obligatorio hasta los setenta años. Es facultativo después de esta edad. ${ }^{16}$

Una innovación que también plantearía gradualmente el incremento en las inscripciones de los partidos o fuerzas políticas en las siguientes contiendas electorales suscitadas desde entonces:

Entre 1978 y el 2002, en el Perú se desarrollaron diecisiete procesos electorales, incluyendo seis elecciones presidenciales y parlamentarias, dos elecciones de Asambleas Constituyentes, un Referéndum y ocho elecciones municipales —incluyendo la última y la reciente elección de gobiernos regionales- ${ }^{17}$

Este asunto nos invita a reflexionar sobre la participación política en las últimas décadas. En el ámbito individual hemos pasado del estigma de que el acceso a un cargo político generaba prebendas, a la presunción de ser propietarios a expensas del mismo, generándose como tradición un conjunto de derechos soslayados como adquiridos. Esto contribuye a restarle obediencia a la autoridad, desnaturalizándose su vocación de servicio, su compromiso y responsabilidad. Por otro lado, están las opciones independientes que aparecen en el escenario político y que revelan la respuesta de algunos sectores de la sociedad ante aquellos partidos que perdieron su referente social. Frente a ello, resulta capital adecuar las reglas de juego que dirige la fuerza electoral imperante. A diferencia de sistemas más cimentados donde predomina el bipartidismo, el Perú optó por el multipartidismo. Ante la carencia de principios rectores previos al proceso electoral, se desató un incremento gradual de alternativas presidenciales y congresales. Si bien una antigua frase sostiene que el papel aguanta todo, lo cierto es que dicha circunstancia nos revela el colapso del sistema. Para afianzarlo, convendría aumentar el número de firmas para las inscripción del partido, derivar la responsabilidad directa del partido político en los trámites conducentes a su inscripción, depurando todo error material — como la duplicidad de las firmas de los adherentes o aquellas fraguadas — bajo sanción de declarar nulo todo lo actuado además de una pena pecuniaria, y establecer una coordinación a cargo del Jurado Nacional de Elecciones (JNE) con los otros poderes y organismos autónomos estatales, requiriendo información de los ciudadanos que postulan a cargos públicos, contando con problemas pendientes con la sociedad y la justicia.

16 Perú. Constitución Política del Perú. 28 de julio de 1980. Lima: Empresa Editora Perú, 1980, p. 19.

17 CÁCERES, Eduardo. «De repente la misma cosa va a ser (reflexiones en torno a identidades, derechos y bienestar en el Perú)». Lima. 2003; cit. NunES, Luis Fernando. «Cultura democrática y elecciones». En Elecciones (Lima), Revista de la Oficina Nacional de Procesos Electorales (ONPE), año 3, nº 3, julio 2004, p. 37. 
Frente a mayores niveles de participación en el sistema electoral, resultaría inadmisible aceptar las candidaturas cuyas trayectorias solo contribuirían a aumentar el desprestigio de los poderes públicos - y el Congreso no es la excepción-. Las constituciones del pasado nos muestran cómo determinadas conductas llevaban a la suspensión del ejercicio de la ciudadanía, sanción que hoy podría entenderse como incompatible en la inscripción de candidatos:

$3^{\circ}$ Tacha por deudor quebrado, o deudor moroso al Tesoro Público. $4^{\circ}$ Por no tener empleo, oficio o modo de vivir conocido. $5^{\circ}$ Los procesados criminalmente. $6^{\circ}$ En los casados que sin causa abandonen a sus mujeres, o que notoriamente falten a las obligaciones de familia. $7^{\circ}$ En los jugadores, ebrios truhanes y demás que con su vida escandalosa ofendan a la moral pública. ${ }^{18}$

Este planteamiento de ningún modo pretende conculcar derecho alguno sino contribuir a fortalecer el perfil del político acorde con la expectativa que de él tiene la ciudadanía.

En cuanto al resultado de la contienda electoral, luego de que los partidos políticos midiesen fuerza, representatividad y vigencia entre el electorado, el Congreso de la República, a través de la Ley de la Barrera Electoral (ley 28617) optó por incidir en el acceso a la distribución de escaños en el Legislativo. Para ello, se determinó que existieran por lo menos seis representantes en más de una circunscripción electoral, equivalente al 5\% del número legal de sus miembros, o de lo contrario haber alcanzado el $5 \%$ de votos válidos en el ámbito nacional. La norma también previó la cancelación de la inscripción del partido en el Registro de Organizaciones Políticas por el Jurado Nacional de Elecciones, luego de transcurrido un año del último proceso electoral general, sea a pedido de los personeros legales o sea de oficio.

Sin embargo, en la misma ley estipuló para el proceso del año 2006 la Disposición Transitoria Única según la cual, y excepcionalmente, se reducía tanto el número de parlamentarios a cinco como el porcentaje de votos a nivel nacional a cuatro por ciento. Por lo demás, se mantenía el tenor del artículo mencionado en la parte relacionada con la vigencia del partido ante el registro correspondiente.

Estos cambios modificaban el tenor de los artículos 20 y 87 de la Ley Orgánica de Elecciones (ley 26859), así como el del artículo 13 de la Ley de Partidos Políticos (ley 28094). Algunos sectores de la sociedad, como la Asociación Civil Transparencia, propusieron el requisito de una medida mínima con la intención de evitar la dispersión de las fuerzas políticas al interior del Legislativo y lograr con ello afianzar el sistema democrático. Al margen de la

18 Artículo 23 de la Constitución de 1823. En García Belaunde, Domingo. Las constituciones del Perú. Tomo I. Lima: Fondo Editorial de la Universidad San Martín de Porres, 2006, p. 129. 
coherencia que muestran las fuerzas políticas en su interior, contar con pocos partidos ayudaría a superar las deficiencias suscitadas en las decisiones jurídico-políticas. Más aún, si nuestro sistema es representativo requiere de solidez para la gobernabilidad del país, pues si bien elegimos personas, ellas deben pertenecer a una tienda política pues no basta la idoneidad del individuo prescindiendo del respaldo partidario. Dicho planteamiento también influyó en una participación política como la actual, que ha contado con más de una veintena de alternativas para la renovación de cargos al interior del Ejecutivo y el Legislativo.

Analizando el sistema político alemán, Omar Handabaka destaca la estabilidad en el funcionamiento de los partidos, la que se ha logrado paulatinamente con la incorporación de los partidos pequeños a los grandes con la idea de lograr su vigencia en el espectro político: «[...] por el buen trabajo de éstos tanto a nivel partidario como en el gobierno y obviamente, por el temor a desaparecer debido a la barrera del cinco por ciento de los votos necesarios para mantener una representación parlamentaria». ${ }^{19}$

El congresista Ántero Flores Araoz, presidente de la Comisión de Constitución, señaló que la valla electoral ya había sido aplicada en el año 1995 y que el argumento de que era antidemocrática carecía de sustento:

[...] pues no debemos olvidar el caso del Dr. Valentín Paniagua, que en las elecciones del 2000 obtuvo un escaño con 14,335 votos por Acción Popular y luego fue electo Presidente del Congreso y Presidente de la República por mandato constitucional; en tanto que otros postulantes con más votos como Luís Gasco Bravo (PAP) con 16,566 votos, Daniel Vera Ballón (PAP) con 15,852 votos o Enrique Chirinos Soto por Perú 2000 con 18,241 votos, pero que su partido no alcanzó escaño al Congreso en la misma elección, no pudieron acceder al Parlamento. ${ }^{20}$

Si bien el artículo 31 de la actual Constitución señala el derecho de los ciudadanos a participar en los asuntos públicos, a ser elegidos y a elegir libremente a sus representantes, recalca también que dicho derecho se ejercita bajo lo que la ley orgánica establezca. Una norma que en forma armoniosa buscó una salida que sustentase la gobernabilidad del sistema con la presencia de pocos partidos, lo que no excluye ni el pluralismo ni la democracia. Muy por el contrario, acepta el interés de las mayorías y minorías, con una tolerancia que implique consenso y disenso: «En otras palabras, no cabe que so pretexto

Handabaka, Omar. «El sistema político alemán: balance y retos». En Elecciones (Lima), Revista de la Oficina Nacional de Procesos Electorales (ONPE), año 3, nº 3, julio 2004, p. 239.

20 Entrevista a Ántero Flores Araoz por Radio Programas del Perú (RPP) Noticias: «Valla electoral no es algo nuevo». Viernes 7 de octubre de 2005. En http://www.rpp.com.pe/portada/ politica/22127_1.php 
de identificar matemáticamente a la democracia representativa con la representación de todos, se termine olvidando que, en realidad, de lo que se trata es que sea una representación para todos». ${ }^{21}$

Si bien el Tribunal Constitucional en el expediente 0030-2005-PI/TC emitió la sentencia del 2 de febrero de 2006 declarando por mayoría infundado el proceso de inconstitucionalidad contra la ley 28617, otorgando toda la fuerza a la vigencia de la norma en cuestión, su aplicación demostrará en los próximos procesos la concurrencia de las fuerzas políticas bajo la figura de partidos funcionales y no de partidocracia, en aras de la cohesión del sistema democrático. Una norma que ha superado una serie de críticas y que no descarta que:

Algunos de los grupos más pequeños van a ver este tema pensando en sus intereses políticos concretos para alcanzar representación en el futuro Congreso porque consideran que esta medida no les permitiría alcanzar representación parlamentaria. Ello se explica por su escaso respaldo en el ámbito nacional. ${ }^{22}$

Por otra parte, no debemos dejar de reconocer la preferencia electoral de las minorías, ya que en el supuesto caso en el que una circunscripción tuviese un ganador con una votación considerable, y aun cuando su partido no consiguiera superar el porcentaje de la valla electoral, excepcionalmente aquel debería ocupar el escaño. Ello en razón al propio origen de la representatividad al encontrar una correspondencia entre el elector y el elegido, postura que recoge también el sistema alemán.

\section{La no reelección en los cargos congresales}

La reelección de Alberto Fujimori Fujimori para un tercer mandato, en mayo del año 2000, generó al interior y exterior del país una serie de cuestionamientos por la legitimidad y el orden jurídico que habían avalado dicha aberración. La precariedad institucional se ponía nuevamente en evidencia y originó una serie de planteamientos que buscaban reencausar el sistema democrático, entre los que se hallaba la reincorporación de los magistrados del Tribunal Constitucional cuyo fallo recogía, vía la interpretación del artículo 112 de la Constitución de 1993, que el proceso electoral de la reelección del mandatario era inconstitucional.

21 STC / 0030-2005-PI/TC 2 de febrero de 2006, fundamento 16.

22 Entrevista a Francisco Eguiguren Praeli. «De no adoptarse una medida como la valla electoral, el próximo Congreso podría ser más fraccionado». Asociación Civil Transparencia. Boletín Mensual III, no 25. En http://www.transparencia.org.pe/web/boltransparencia/ boletin25.pdf.

Ver también «La valla electoral ya tiene el visto bueno del Constitucional». http:// www.perupolitico.com/?p=192 
Pese a esa elección, que incluyó la renovación de cargos congresales, el partido oficial no obtuvo mayoría en el Legislativo. Sin embargo, entre la elección y la toma de posesión de los cargos, algunos congresistas elegidos abandonaron su partido político para formar parte del oficialista Cambio 90-Nueva Mayoría, una actitud que traía por los suelos la correspondencia entre el elector y el elegido, con el agravante que se elegía por distrito único. Sin embargo, la propalación del video en el que se veía al asesor presidencial Vladimiro Montesinos proporcionando una suma de dinero a Alberto Kouri a cambio de que pasase a integrar las filas del oficialismo, dejó al descubierto lo que se conocía por testimonio de terceros, un escándalo que apresuró el final del mandato político de Fujimori, establecido originalmente hasta el año 2005, pues colocaba en tela de juicio la credibilidad y legitimidad del sistema. Ello obligó a llevar a cabo una reforma constitucional a través de la ley 27365 que estipuló el recorte del mandato de los congresistas elegidos y del propio Presidente de la República para el mes de julio de 2001. ${ }^{23}$

Bajo este mismo razonamiento, y desde noviembre del año 2005, en Moquegua se recolectaban firmas con el propósito de evitar dicha reelección en los cargos congresales. El plan de gobierno 2006-2011 del Partido Nacionalista Peruano en el rubro de la reforma del Estado postuló eliminar tanto la reelección presidencial inmediata como la reelección parlamentaria, la reelección de alcaldes y regidores municipales, y la reelección inmediata de presidentes regionales y consejeros regionales. ${ }^{24}$ Esta circunstancia hizo reflexionar sobre la actuación del elegido, su trayectoria, el cumplimiento de su promesa electoral y su aspiración a la prórroga en el mandato del cargo, lo cual no escapaba a la existencia de cierto clientelismo con la mayoritaria población electoral carente de servicios básicos.

Dicho planteamiento puso a prueba las estrategias de los demás partidos políticos en la contienda de 2006, obligando a que los candidatos al Congreso Nacional no fuesen los que se hallaban en funciones. No debemos descartar en esta idea la adherencia de un sector de la población, motivando el rediseño de las listas como fue el caso de Unidad Nacional y Perú Posible, que trasladaron candidatos de la lista al Congreso Nacional a la del Parlamento Andino, o de lo contrario, optando por excluirlos del proceso electoral. Nuevamente se ponía en discusión el ámbito normativo debido a que la Ley de Partidos Políticos no había considerado tal postura:

23 Landa Arroyo, César. «Proceso electoral proceso constitucional y electoral». En http:// palestra.pucp.edu.pe/palelec/index.php3?file=procesoelect/landa $1 . \mathrm{htm}$

24 http://www.partidonacionalistaperuano.com/docs/RESUMEN_EJECUTIVO_FINAL.pdf 
Artículo $24^{\circ}$ Modalidades de elección de candidatos

Corresponde al órgano máximo del partido político decidir la modalidad de elección de los candidatos a los que se refiere el artículo anterior.

Para tal efecto, al menos las cuatro quintas partes del total de candidatos a representantes del Congreso, Consejeros, Regionales o Regidores, deben ser elegidos bajo alguna de las siguientes modalidades:

a) Elecciones con voto universal, libre, voluntario, igual, directo y secreto de los afiliados y ciudadanos no afiliados

b) Elecciones con voto universal, libre, voluntario, igual, directo y secreto de los afiliados.

c) Elecciones a través de órganos partidarios, conforme lo disponga el Estatuto. [...].

Esta situación hizo que otras fuerzas políticas, como el Partido Aprista Peruano, adoptasen una postura mixta donde la lista de candidatos al Congreso estuviese compuesta por congresistas que iban a la reelección y por nuevos postulantes, bajo el amparo de la Ley de Partidos Políticos que no colocaba restricciones al respecto. Los legisladores del nuevo Parlamento deberán confirmar la norma en vigencia o decidir por la no reelección, lo cual obligaría a los partidos a preparar en forma nominal y real nuevos cuadros de dirigencia política, más allá de la disciplina y de la obediencia al jefe, presidente de partido, fundador o líder carismático, en la búsqueda de una cultura política institucional y funcional que deje de lado la partidocracia. Considerando que los partidos se renuevan con cierta periodicidad, y que en consecuencia surgen nuevos legisladores que carecen de experiencia, debe preverse la continuidad de un grupo de funcionarios congresales que aseguren el manejo productivo de la institución, cuya estabilidad laboral y remuneración dependa de la administración encarnada en la Oficialía Mayor del Congreso, en un proceso de reforma integral del propio Parlamento que reencauce el verdadero sentido de los cargos políticos.

\section{Tareas pendientes}

\subsection{El voto para los presos no sentenciados}

Desde la Constitución de 1979 la ciudadanía aumentó, pues a partir de entonces, para ser ciudadano sólo había que tener más de 18 años de edad y no estar procesado judicialmente o estar sentenciado. Desde finales de la legislaturas de la década de 1990, se habían presentado proyectos en la Comisión de Constitución del Congreso para permitir el derecho al voto a aquellos ciudadanos cuya situación judicial no estuviese aclarada, hallándose recluidos pero 
no sentenciados. El asunto suele en principio ser complejo ya que, por un lado, se busca aclarar con mayor velocidad la situación de los detenidos, y por otro, permitir el ejercicio del derecho al sufragio.

El 2 de noviembre de 1998, Gilberto Siura y Óscar Medelius fundamentaron el proyecto que permitiría el sufragio de los detenidos en las elecciones generales del año 2000, ya que era por distrito único. En este proyecto se señalaba que la Oficina Nacional de Procesos Electorales (ONPE) instalaría mesas de sufragio en los establecimientos penales. Javier Alva Orlandini se opuso, al no extenderse el voto también a las elecciones municipales, mientras que Jorge del Castillo lo hizo alegando que en dichas circunstancias podía darse una injerencia partidaria bajo mecanismos de presión con tal de que el voto favoreciera al oficialismo. En 1998, unos diecisiete mil detenidos en el ámbito nacional era un número de votos interesante para cualquier candidato. Siura esperaba contar con el respaldo de la bancada Cambio 90 Nueva Mayoría antes de la clausura de la correspondiente legislatura. Incluso el entonces jefe del Instituto Nacional Penitenciario, el general Juan Nakandakari, indicó que no habría riesgo de fuga en el desarrollo del proceso:

Las campañas políticas serían muy interesantes. Los candidatos tendrían que animarse a recorrer los penales — si es que los dejan entrar- como lo hacen en los mercados y calles. Sus ofertas, suponemos, deberán ser atractivas para su eventual auditorio. Esperamos que no abunden los demagogos que ofrezcan reducciones drásticas de las penas, eliminación del Código Penal o beneficios penitenciarios de cinco por uno —un día trabajado redime cinco días de cárcel-.$^{25}$

Por otro lado, había expectativas respecto de quienes serían designados miembros de mesa, así como si se contaría con la presencia de personeros en los centros de reclusión, salvo que en ambos casos fuesen los titulares los mismos internos. Cierto es que la peculiar circunstancia demandaba establecer mesas de sufragio transitorias. Bajo el sistema electoral de entonces por distrito único y con los escaños que no exigían un número mayor que cuatro mil votos, el proyecto de Siura generaba expectativa. Un planteamiento que también fue considerado dentro de la propuesta para un acuerdo naciona ${ }^{26}$ puesta a consideración en el año 2000, aludida en la primera parte de este artículo:

25 Perú Sistema Penitenciario. «Proyecto sobre el voto de los presos aguarda debate». Publicado el 17 de noviembre de 1998. En http://www.elcomercioperu.com.pe

26 «Propuesta para un acuerdo político nacional». Lima, 26 de junio del 2000. En http:// www.transparencia.org.pe/web/pronunciamientos/acuerdo.rtf. 
4.3 Garantizar el derecho a elegir de discapacitados y presos no sentenciados

a. Crear mecanismos que permitan el ejercicio del voto de los ciudadanos con discapacidad.

b. Establecer mesas de sufragio en los centros penitenciarios para permitir el derecho del voto de los presos no sentenciados.

Durante el actual período congresal, en el año 2003, el legislador César Acuña Peralta presentó un nuevo proyecto con la intención de que los presos no sentenciados puedan ejercer el derecho al voto, considerando que en la actualidad veinticinco mil internos en todo el país — $70 \%$ del total de internospodrían sufragar. La futura norma demandaría la colaboración del Instituto Nacional Penitenciario (INPE), quien se encargaría de elaborar la relación de internos en condición de detenidos sin sentencia que hay en el país. Luego, le correspondería al RENIEC, en colaboración con la ONPE y el JNE, elaborar las listas, considerando los llamados a sufragar, así como instalar las mesas de transeúntes al momento de las elecciones. No obstante, este proyecto no llegó a cristalizarse. Durante el proceso electoral del 2006 los presos por delito de corrupción —alrededor de treinta- y que contaban con arresto domiciliario, solicitaron la autorización ante la ONPE para votar, según la Dirección de Seguridad de Penales (DIRSEPEN).

Entre los autorizados a votar está el coronel EP Víctor Silva Mendoza, ex jefe del Servicio de Inteligencia del Ejército, vinculado al grupo Colina, quien irá a una mesa de Barranco. También están los generales Carlos Bergamino Cruz, Jorge Girano Soto, Abraham Cano Angulo, Walter Chacón Málaga, Juan Yanqui Cervantes, Ricardo Sotero Navarro, Walter Jave Huangal, Jorge Malpartida. Pero no solo ellos, también sufragarán Orlando Montesinos Torres - hermano del Doc_- los ex vocales Alipio Montes de Oca y Lorenzi Goicochea; los hermanos Áybar Cancho, comprometidos en el tráfico de armas para las FARC colombianas así como Marden Rojas Aranda, procesado por estafa. Igualmente Carlos Echevarría Quevedo, juzgado por violación y Pedro Santillán Galdós, por tráfico de drogas. ${ }^{27}$

La DIRSEPEN diseñó un plan que contó con la presencia de efectivos, llevándolos a los centros de votación para luego retornarlos a sus domicilios.

\subsection{La eliminación del voto preferencial}

La Asamblea Constituyente de 1978 innovó el proceso electoral al establecer por primera vez el voto preferencial. El decreto ley 21995, del 15 de noviembre de 1977, permitió la cifra con circunscripción electoral uninominal, según

«Presos por corrupción pidieron emitir su voto». En El Comercio, 6 de abril del 2006. En http://weblogs.elearning.ubc.ca/peru/archives/024973.php. 
la cual el voto determinaba no solo la simpatía del elector por una fuerza política sino además por el político con mayor carisma, reconocimiento o popularidad al interior de esta. Según Tuesta Soldevilla, con la introducción del voto se generaba lo siguiente:

1. Movilidad de puestos entre los candidatos que salieron elegidos, notándose más en los frentes que en los partidos.

2. Una gran cantidad de candidatos ubicados en puestos rezagados logran conquistar un escaño.

3. Descubrir que el último de la lista es tan beneficiado como el primero.

4. El voto preferencial puede dejar de lado a algunas figuras que, a pesar de su participación destacada en los ámbitos localizados en la vida nacional, no lo son para recibir el apoyo del voto preferencial. ${ }^{28}$

El voto preferencial se producía por lista cerrada donde el sufragante escogía entre una relación de candidatos proporcionada por el partido. Roisida Aguilar señalaba que el Partido Aprista Peruano fue reacio a esta modalidad de voto, «[...] argumentando que la dictadura militar quería dividir el voto de dicha agrupación partidaria y con ello evitar que su líder Víctor Raúl Haya de la Torre obtuviera la mayor votación». ${ }^{29}$

Los hechos demostrarían lo contrario, pues gracias a dicho voto Haya de la Torre terminó siendo presidente de la Asamblea Constituyente. Con ello se gestaría la costumbre de que luego del proceso electoral, al político con mayor votación le corresponde ocupar, al inicio de la siguiente legislatura, el cargo de presidente del Congreso. La experiencia electoral del voto preferencial en la década de 1990, tanto en las campañas electorales como en su funcionamiento, terminó por otorgar más importancia al candidato que al partido, debilitando la propuesta de este sector de la sociedad. Crítica que el ex Presidente de la República, Valentín Paniagua, formuló a la Comisión de Constitución de la actual legislatura: «El voto preferencial ha demostrado que tiene algunas características que resienten las relaciones internas dentro de los partidos. Obligan en la práctica a que los miembros de una misma lista compitan recíprocamente». ${ }^{30}$

Tuesta Soldevilla, Fernando. Perú político en cifras. Élite política y elecciones. Lima: Fundación Friedrich Ebert, 1994, p. 28.

29 OnPe-Cie. Los procesos electorales en el Perú 1978-1986. Problemas y lecciones. Lima: ONPECIE, 2005, p. 12.

30 «Paniagua pide al Congreso eliminar voto preferencial». En La República, 5 de septiembre de 2005. http://www.laultima.com/noticia.php?id=13753\&idcategoria=2\&seccion= Pol\%C3\%ADtica. 
El individualismo al interior de los partidos había llegado a tal punto que podía romper la correspondencia entre el elector y el elegido, como lo demostró el video Kouri-Montesinos que rebasó la tolerancia política al mostrar la compra de políticos elegidos, más aún cuando el voto preferencial había favorecido la elección de políticos que traicionaron a sus electores: «[...] dicho sistema posibilita que supuestos delincuentes y violadores puedan llegar al Congreso, tras haber vendido una imagen distinta a la población, que finalmente acaba engañada y decepcionada de la política». ${ }^{31}$

Pese a los cuestionamientos, no se logró obtener la votación requerida para la eliminación del voto preferencial, y mientras tanto, se mantuvo lo estipulado en el artículo 21 de la Ley Orgánica de Elecciones (ley 26859):

Los Congresistas de la República son elegidos mediante sufragio directo, secreto y obligatorio. La elección de Congresistas a la que se refiere el artículo 90 de la Constitución Política del Perú se realiza mediante el sistema del Distrito Electoral Múltiple, aplicando el método de la cifra repartidora, con doble voto preferencial opcional, excepto en los distritos electorales donde se elige menos de dos congresistas en cuyo caso hay un solo voto preferencial [...].

Queda a consideración del nuevo Parlamento su eliminación en un contexto donde las individualidades han contribuido, junto a la reelección política en nuestras incipientes instituciones, a reforzar el clientelismo más que a rescatar el verdadero sentido de la política en beneficio del país. ${ }^{32}$

\section{Conclusiones}

Si la política significa crear el ambiente necesario para la vida buena, resulta necesario mostrar que las instituciones deben ir al compás de los cambios en beneficio del sistema democrático, integrando a los diferentes grupos de la sociedad, pero custodiando que las nuevas autoridades no comprometan a las instituciones políticas con una conducta social y legalmente impropia.

Para ello se requiere fomentar la participación de fuerzas políticas que sirvan de contrapeso al partido oficial, fomentar la crítica constructiva desde la sociedad o desde los poderes políticos y que se utilice el ordenamiento jurídico y la propia Constitución como los instrumentos más idóneos. Esta participación,

31 «Mesa Redonda Elecciones 2006». El Comercio. Luis Benavente, Grupo Opinión de la Universidad de Lima. En http://www.elcomercioperu.com.pe/Elecciones2006/Html/2005-1027/MesaRedonda0393371.html.

32 CASAS, Kevin. «El voto preferencial, de nuevo. El voto preferencial aumenta el clientelismo, la corrupción y el mal uso de los fondos». 24 de julio del 2005. En http://www.transparenciacr.org/ ver.php/485 
que es sinónimo de democracia, debe complementarse con la educación, pasando de la cultura cívica a la política para que los ciudadanos asuman su responsabilidad en el derecho de elección, concediendo un plazo razonable a los elegidos para que ellos demuestren la eficiencia en la administración del país.

No descartamos la importancia del individuo, que es fundamental para conservar el liderazgo, pero bajo reglas ya establecidas, haciendo convivir la praxis política con un sistema que puede modificarse, pues ante todo constituye un producto humano $y$, por lo tanto, imperfecto. 